\title{
Mudanças e perspectivas no setor de entrega urbana de produtos em uma cidade média devido à pandemia da COVID-19
}

Changes and perspectives in the urban product delivery sector in a medium-sized city due to the COVID-19 pandemic

Resumo: 0 comércio e o transporte urbano de produtos passam, desde março de 2020, por um período de grandes incertezas provocadas pelo surto epidêmico da COVID-19. Nesse contexto, o objetivo deste artigo é estudar as alterações nos padrões de venda e de transporte de produtos na cidade de Campos dos Goytacazes devido à pandemia. Além disso, compreender quais foram as primeiras soluções encontradas pelos varejistas para a questão da entrega urbana de produtos e quais dessas medidas têm o potencial de uso pós-pandemia. Assim, desenvolveu-se uma pesquisa por meio da aplicação de um questionário para uma amostra de 69 lojistas na cidade. Os principais resultados apontam para a ampliação do uso de canais eletrônicos e entregas em domicílio, com o potencial de permanecer de forma perene.

Palavras-chave: COVID-19. Comércio. Logística urbana. Transporte.
Abstract: Since March 2020, the trade and urban transport of products have gone through a time of great uncertainties caused by the epidemic outbreak of COVID-19. In this context, the objective of this article is to study changes in the patterns of sale and transportation of products in the city of Campos dos Goytacazes, Rio de Janeiro State, Brazil, due to the pandemic of COVID-19. Moreover, understand what were the first solutions found by retailers to the issue of urban delivery of products and which of these measures have the potential for post-pandemic use. Thus, a survey was developed by means of the application of a questionnaire to a sample of 69 shopkeepers in the city. The main results point to the expansion of the use of electronic channels and home deliveries, with the potential to remain permanent.

Keywords: COVID-19. Commerce. Urban logistics. Transportation.

\section{Geísa Pereira Marcilio Nogueira}

Doutoranda em Planejamento Regional e Gestão da Cidade pela Universidade Candido Mendes - Campos. Mestre e graduada em Engenharia de Produção pela Universidade Candido Mendes - Campos. E-mail: isamarcilio@yahoo.com.br.

\section{João José de Assis Rangel}

Doutor em Administração pela Fundação Getúlio Vargas (FGV). Universidade Federal Fluminense, Centro de Estudos Sociais Aplicados, Faculdade de Administração e Ciências Contábeis.

\section{Paulo Rossi Croce}

Mestrando em Sistemas Aplicados à Engenharia e Gestão pelo Instituto Federal Fluminense - Campus-Campos/Centro. Graduado em Engenharia Mecânica pela Universidade Candido Mendes - Campos. E-mail: paulorossicroce@gmail.com.

\section{Eduardo Shimoda}

Doutor e mestre em Produção Animal pela Universidade Estadual do Norte Fluminense Darcy Ribeiro. Professor no curso de Mestrado em Pesquisa Operacional e Inteligência Computacional na Universidade Candido Mendes - Campos. E-mail: shimoda@ucam-campos.br. 


\section{Introdução}

0 atual cenário de crise provocado pela síndrome respiratória aguda grave - coronavírus 2 (da sigla em inglês, SARSCoV-2, Severe Acute Respiratory Syndrome-coronavirus 2), mais conhecida como COVID-19, tem impactado as relações sociais e econômicas ao redor do mundo (KISSLER et al., 2020). Com isso, a cadeia de suprimentos (CS) como um todo e as atividades logísticas também enfrentam uma situação atípica de riscos, conforme explicado por Ivanov (2020). Segundo o autor, tais riscos se observam pela existência de interrupção em longo prazo da CS, propagação simultânea de interrupções, isto é, efeito cascata e interrupções simultâneas na oferta, na demanda e na infraestrutura logística. Como exemplo, as atividades de transporte são fortemente impactadas não só pela falta de abastecimento como também pela alteração nos fluxos de transporte urbano e nos níveis de atendimento aos clientes.

No contexto da logística urbana, o comércio tradicional (baseado nos deslocamentos dos clientes até os locais de venda) e a ampliação das compras realizadas por meio do comércio eletrônico levaram a uma reestruturação do sistema logístico alterando o padrão de distribuição de mercadorias. Independentemente da modalidade de comércio, o aumento do fluxo de bens trouxe grandes mudanças para os espaços urbanos e para o estilo de vida das populações, principalmente em grandes centros comerciais (CASTILLO et al., 2018). De acordo com Arnold et al. (2018), os problemas urbanos mais comuns originados a partir da logística de distribuição de produtos derivam da intensificação do fluxo de veículos, o que provoca congestionamentos, ruídos e aumento nos níveis das emissões de gases de efeito estufa.

Diante disso, é necessário estudar os processos mercadológicos e logísticos que influenciam no espaço urbano durante uma situação de crise. A respeito disso, cita-se o impacto direto na economia local em que os lojistas precisam se adaptar às condições atuais de mercado a fim de superarem as restrições de funcionamento impostas pelos governos. Dado o contexto, o objetivo deste artigo é estudar as alterações nos padrões de venda e de transporte de produtos na cidade de Campos dos Goytacazes devido à pandemia da COVID-19. Além disso, compreender quais foram as primeiras soluções encontradas pelos varejistas para a questão da entrega urbana de produtos e quais dessas medidas têm 0 potencial de uso pós-pandemia.

\section{Algụns dos efeitos econômicos, sociais e ambientais da pandemia}

Devido à crise global da COVID-19, a maior parte dos governos tomou ações preventivas, como o distanciamento social e o confinamento (lockdown), a fim de reduzir o número de vítimas. A disseminação da doença e as medidas restritivas impostas têm impactado todos os setores da sociedade, com uma grande perda mundial muito difícil de ser estimada. Além disso, provocaram diversos impactos sociais, econômicos e ambientais nas cidades (NAKADA; URBAN, 2020).

Os eventos sociais que geram aglomerações foram temporariamente suspensos desde março de 2020, ea movimentação das pessoas em espaços públicos, nesse período, é justificada apenas quando não há alternativa. Com isso, rapidamente perceberam-se alterações na produção do espaço urbano e no estilo de vida de toda a sociedade. Do ponto de vista turístico, o fechamento de aeroportos extinguiu diversas atividades de negócios e/ou lazer que contribuem para a economia internacional. Por outro lado, também se observa a falta de medicamentos, produtos higienizadores, entre outros, criando um aumento exacerbado nos seus preços. Indo além, existe outra questão social ainda mais grave que essa: uma grande parcela da população está impossibilitada de ocupar seus postos de trabalho, o que acaba elevando o índice de desemprego (ALI; ALHARBI, 2020).

A ocorrência de impactos sociais, como o desemprego, tem desencadeado sérios problemas na economia em nível mundial. A esse respeito, a interrupção de processos

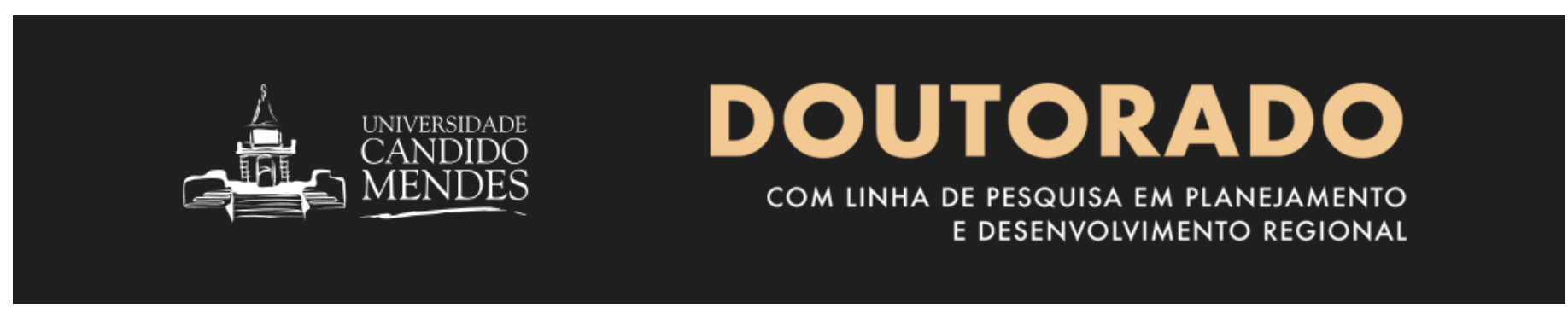


produtivos de bens de consumo e/ou bens de base, por exemplo, pode significar um colapso na produção. Com a atividade industrial em baixa, todo o mundo é afetado economicamente de maneira negativa. Já em nível local, os impactos podem causar o encerramento das atividades de estabelecimentos comerciais de pequeno e médio porte, comprometendo, com isso, o desenvolvimento local e regional (ALI; ALHARBI, 2020).

Contrapondo os efeitos negativos já esperados na sociedade e na economia, tem ocorrido, em nível ambiental, uma melhoria na qualidade do ar em grandes cidades ao redor do mundo, resultante da diminuição do tráfego de veículos movidos a combustíveis fósseis. Observou-se, por exemplo, uma diminuição de alguns tipos de partículas inaláveis na China (ZAMBRANO-MONSERRATE; RUANO; SANCHEZ-ALCALDE, 2020), em algumas regiões da Índia (SHARMA et al., 2020) e na cidade de Barcelona (TOBÍAS et al., 2020). No Brasil, esse comportamento não foi diferente. Uma pesquisa sobre a qualidade do ar durante o confinamento parcial na cidade de São Paulo mostrou uma redução drástica nos níveis das emissões de diversos gases que provocam o efeito estufa. Por outro lado, a concentração de ozônio aumentou cerca de 30\% nas áreas urbanas influenciadas por tráfego de veículos (NAKADA; URBAN, 2020). Um estudo semelhante no município do Rio de Janeiro também mostrou reduções de partículas inaláveis em diversos bairros cariocas (DANTAS et al.,2020)

\section{Considerações sobre o transporte urbano de produtos}

Em uma escala urbana, os movimentos de mercadoria podem ser considerados a partir de três tipos distintos de fluxos, conforme explicado por Comi; Nuzzolo (2016). Os autores chamam o primeiro de fluxo de passageiros, 0 qual se origina a partir das viagens dos consumidores até as lojas para efetuarem uma compra e, posteriormente, retornarem para seus locais de origem. 0 segundo fluxo mencionado é o fluxo dos veículos comerciais que se deslocam em um determinado espaço urbano a fim de reabastecerem o estoque das lojas. 0 último compreende as viagens dos veículos comerciais destinados a realizar as entregas de produtos nos domicílios dos consumidores; um fluxo específico do comércio eletrônico.

Conforme destacado por Crainic; Montreuil (2016), o sistema de transporte urbano atua como uma rede complexa composta por diferentes tipos de entidades. As principais são as mercadorias e/ou pessoas (entidades transportadas), os veículos e as infraestruturas pelas quais os veículos se deslocam (as vias em geral) e, por fim, os terminais logísticos públicos e privados (tais como centros de distribuição, portos, aeroportos, entre outros). Quando qualquer um desses elementos passa por uma interferência, seja interna, seja externa, é comum que haja um desequilíbrio sistêmico, podendo causar sérios danos capazes de refletir em problemas de ordem social, ambiental ou econômica. Trazendo um exemplo notável no setor de transporte, pode-se lembrar da greve dos caminhoneiros no Brasil, também chamada de Crise do Diesel, ocorrida em maio de 2018. Naquela ocasião, a paralização de caminhoneiros autônomos em todo o território nacional desencadeou um aumento da inflação e a queda do Produto Interno Bruto (MOURA et al., 2019).

A partir disso, cabe uma reflexão sobre a interferência dos fatores mencionados por Crainic; Montreuil (2016) na distribuição de mercadorias nas áreas urbanas e como isso afeta a qualidade de vida das pessoas. A existência, cada vez mais intensa, de movimentações de veículos no espaço urbano torna-se um processo desafiador tanto para os lojistas como para os consumidores. Os principais problemas provocados pelas atividades de transporte de mercadorias em área urbana densamente povoadas incluem os congestionamentos causados pelos veículos pesados, os ruídos e as emissões de poluentes atmosféricos (MASSON et al., 2017).

Diante disso, surge a necessidade de que o planejamento e as políticas da cidade levem em consideração as mudanças que ocorrem no âmbito da logística. Uma mudança de paradigma no transporte urbano de mercadorias pode criar novas formas de participação dos atores envolvidos, a saber, o poder público, os empresários e os consumidores (IGNAT; CHANKOV, 2020). Além disso, os processos sociais que dão origem à logística da cidade e ao transporte urbano precisam ser levados em consideração assim como o fluxo de mercadorias das empresas e a regulamentação governamental (GAMMELGAARD, 2015).

\section{Decretos governamentais durante a pandemia e impactos no fluxo de mercadorias}

A seguir, pode-se identificar como o Estado tem assumido a sua função de executor e regulador de políticas à medida que tem criado uma série de ferramentas regulatórias durante o período da pandemia para conter a propagação da COVID-19. Sendo assim, diversos decretos estaduais e municipais dispõem sobre medidas diretamente relacionadas às atividades comerciais, 
conforme apresentado no Quadro 1. Em Campos dos Goytacazes, assim como em outros municípios, os estabelecimentos considerados essenciais, tais como supermercados, farmácias e postos de combustíveis, puderam manter o funcionamento, respeitando-se algumas medidas preventivas como o uso de máscaras e o distanciamento social. Em contrapartida, atividades comerciais consideradas não essenciais, como vendas de eletrodomésticos, equipamentos eletrônicos entre outros, tiveram suas atividades interrompidas.

É evidente que a COVID-19 não trouxe apenas problemas relacionados à saúde das pessoas, visto que desencadearam, em nível econômico, impactos negativos no comércio local. Todas essas mudanças ocorridas a partir do mês de março de dois mil e vinte modificaram o padrão de comércio local, baseado em vendas presenciais, para uma nova abordagem centrada na entrega de produtos em domicílio, como ocorre no comércio eletrônico. Dessa forma, o fluxo das mercadorias na cidade passou a contar, quando possível, com a utilização de veículos comerciais, e as empresas locais foram obrigadas a passar por um processo de adaptação na busca pela sobrevivência do seu negócio.

Quadro 1: Decretos estaduais e municipais que influenciaram no funcionamento do comércio e impactaram o transporte de mercadorias.

\begin{tabular}{|c|c|c|}
\hline Esfera & Decreto & Escopo \\
\hline \multirow{7}{*}{ Estadual } & Decreto n. ${ }^{\circ} 46.966$ de $11 / 03 / 2020$ & $\begin{array}{l}\text { Dispõe sobre medidas como isolamento e quarentena para } \\
\text { enfrentamento da emergência de saúde decorrente do } \\
\text { coronavirus. }\end{array}$ \\
\hline & Decreto $\mathrm{n}^{\circ} 46.973$ de $16 / 03 / 2020$ & $\begin{array}{l}\text { Adota medidas de enfrentamento da propagação do } \\
\text { coronavirus, como fechamento de centros comerciais e } \\
\text { restrição de lotação em estabelecimentos. }\end{array}$ \\
\hline & Decreto n. ${ }^{\circ} 46.989$ de $24 / 03 / 2020$ & $\begin{array}{l}\text { Dispõe sobre o funcionamento de pequenos estabelecimentos } \\
\text { de vendas de alimentos, bebidas e dá outras providências. }\end{array}$ \\
\hline & Decreto $\mathrm{n}^{\circ} 47.001$ de $26 / 03 / 2020$ & $\begin{array}{l}\text { Dispõe sobre o funcionamento de estabelecimentos destinado } \\
\text { a venda de material de construção, ferragem e de equipamento } \\
\text { de proteção individual, e dá outras providências. }\end{array}$ \\
\hline & Decreto n. ${ }^{\circ} 47.002$ de $26 / 03 / 2020$ & $\begin{array}{l}\text { Dispõe sobre o funcionamento da indústria de óleo e gás } \\
\text { onshore, e dá outras providências. }\end{array}$ \\
\hline & Decreto n. ${ }^{\circ} 47.021$ de 06/04/2020 & $\begin{array}{l}\text { Autoriza o funcionamento de estabelecimentos comerciais, } \\
\text { apenas em regime de entrega em domicilio ou sistema drive } \\
\text { thru, sem atendimento presencial. }\end{array}$ \\
\hline & $\begin{array}{l}\text { Decreto }{ }^{\circ} 47.022 \text { de } 07 / 04 / 2020 \\
\text { Decreto } n .^{\circ} 47.025 \text { de } 07 / 04 / 2020\end{array}$ & $\begin{array}{l}\text { Autoriza o funcionamento de estabelecimentos comerciais, } \\
\text { apenas em regime de entrega em domicílio. } \\
\text { Dispõe sobre a liberação de atividade comercial em } \\
\text { municípios sem notificação de cometimento da COVID-19, e } \\
\text { dá outras providências. }\end{array}$ \\
\hline \multirow{6}{*}{ Municipal } & Decreto ${ }^{\circ} 33$ de $20 / 03 / 2020$ & $\begin{array}{l}\text { Suspende } \circ \text { atendimento presencial ao público em } \\
\text { estabelecimentos comerciais em funcionamento no municipio } \\
\text { entre } 23 \text { de março e } 5 \text { de abril de } 2020 \text {. }\end{array}$ \\
\hline & Decreto . $^{\circ} 51$ de $03 / 04 / 2020$ & $\begin{array}{l}\text { Suspende } \circ \text { atendimento presencial ao público em } \\
\text { estabelecimentos comerciais em funcionamento no municipio } \\
\text { entre } 6 \text { e } 19 \text { de abril de } 2020 \text {. }\end{array}$ \\
\hline & Decreto n. $^{\circ} 61$ de $18 / 04 / 2020$ & $\begin{array}{l}\text { Suspende } \circ \text { atendimento presencial ao público em } \\
\text { estabelecimentos comerciais em funcionamento no municipio } \\
\text { entre } 19 \text { e } 30 \text { de abril de } 2020 \text {. }\end{array}$ \\
\hline & Decreto $n^{\circ} 75$ de $30 / 04 / 2020$ & $\begin{array}{l}\text { Suspende } \circ \text { atendimento presencial ao público em } \\
\text { estabelecimentos comerciais em funcionamento no municipio } \\
\text { até } 11 \text { de maio de } 2020 \text {. }\end{array}$ \\
\hline & Decreto n. $^{\circ} 90$ de $11 / 05 / 2020$ & $\begin{array}{l}\text { Suspende } \circ \text { atendimento presencial ao público em } \\
\text { estabelecimentos comerciais em funcionamento no municipio } \\
\text { até } 24 \text { de maio de } 2020 \text {. }\end{array}$ \\
\hline & Decreto n. ${ }^{\circ} 100$ de $16 / 05 / 2020$ & $\begin{array}{l}\text { Veda a qualquer indivíduo a permanência e o trânsito em vias, } \\
\text { parques, equipamentos, locais e praças públicas, dentro do } \\
\text { Municipio, entre } 18 \text { e } 24 \text { de maio de } 2020 \text {. }\end{array}$ \\
\hline
\end{tabular}




\section{Metodologia}

Este estudo é baseado em um método quantitativo de coleta de dados primários no qual se utilizou uma pesquisa de campo com a aplicação de um questionário estruturado (GIL, 2010). Em decorrência da pouca disponibilidade de literatura sobre o tema, visto ser uma ocorrência sem precedentes, esta pesquisa tem um caráter exploratório, assumindo a forma de um estudo de caso, conforme classificado por Gil (2010), e representa uma versão preliminar de um estudo em curso, tendo em vista a contemporaneidade do problema investigado.

0 questionário foi desenvolvido por meio da ferramenta de pesquisa eletrônica do sistema Google e enviado por e-mail e WhatsApp Messenger para os respondentes. Essa abordagem foi utilizada devido à necessidade de distanciamento social causada pela pandemia. Assim, todos os dados dessa pesquisa foram obtidos de forma on-line. Dadas as restrições atuais de mobilidade, considerou-se essa escolha adequada e eficiente, tendo sido, inclusive, utilizada anteriormente em outros estudos (MEE; HUEI, 2015; OLIVEIRA et al., 2017) nos quais resultados interessantes puderam ser obtidos. Por outro lado, ressalta-se que existem algumas limitações na pesquisa on-line, como diferenças de entendimento e interpretação e falta de respostas conscientes. A fim de minimizar esses problemas, realizou-se o pré-teste do questionário, para verificar sua abrangência, objetividade e facilidade, além de impedir que as perguntas fossem enviadas mais de uma vez pelo mesmo respondente.

Os questionários on-line foram aplicados durante a segunda quinzena de maio de 2020 a 69 lojistas que possuem estabelecimentos comerciais em Campos dos Goytacazes. Esse município está localizado no estado do
Rio de Janeiro, na Mesorregião Norte Fluminense. De acordo com o Censo 2010, possui uma população de 463.731 habitantes e densidade demográfica de 115,16 hab/ $\mathrm{km}^{2}$. A população estimada pelo Instituto Brasileiro de Geografia e Estatística (IBGE), em 2019, é de 507.548 habitantes, e sua extensão territorial é de 4.032, 487 $\mathrm{km}^{2}$. 0 salário médio mensal dos trabalhadores formais (2017) é de 2,5 salários mínimos, sendo eles apenas 19,6\% da população (IBGE CIDADES, 2020).

\section{Resultados preliminares do impacto da pandemia no comércio local e seus desdobramentos}

Os resultados obtidos por meio dos questionários indicam que um dos principais impactos causados pela pandemia no comércio varejista de Campos dos Goytacazes diz respeito às mudanças nos padrões de funcionamento das lojas, conforme pode ser observado na Tabela 1. Não é possível estimar quantos negócios foram fechados nesse período, impedindo, inclusive, a obtenção de uma amostra maior para a pesquisa. Dos 69 estabelecimentos entrevistados, 50 (72,46\%) estão funcionando com algum tipo de restrição, seja de horários e/ou de capacidade de pessoas, enquanto 13 $(18,84 \%)$ sequer estão funcionando. Apenas 6 (8,70\%) estabelecimentos declararam que estão funcionando totalmente. Observa-se, ainda, que essas limitações têm afetado todos os segmentos comerciais, sejam os considerados essenciais, sejam os não essenciais.

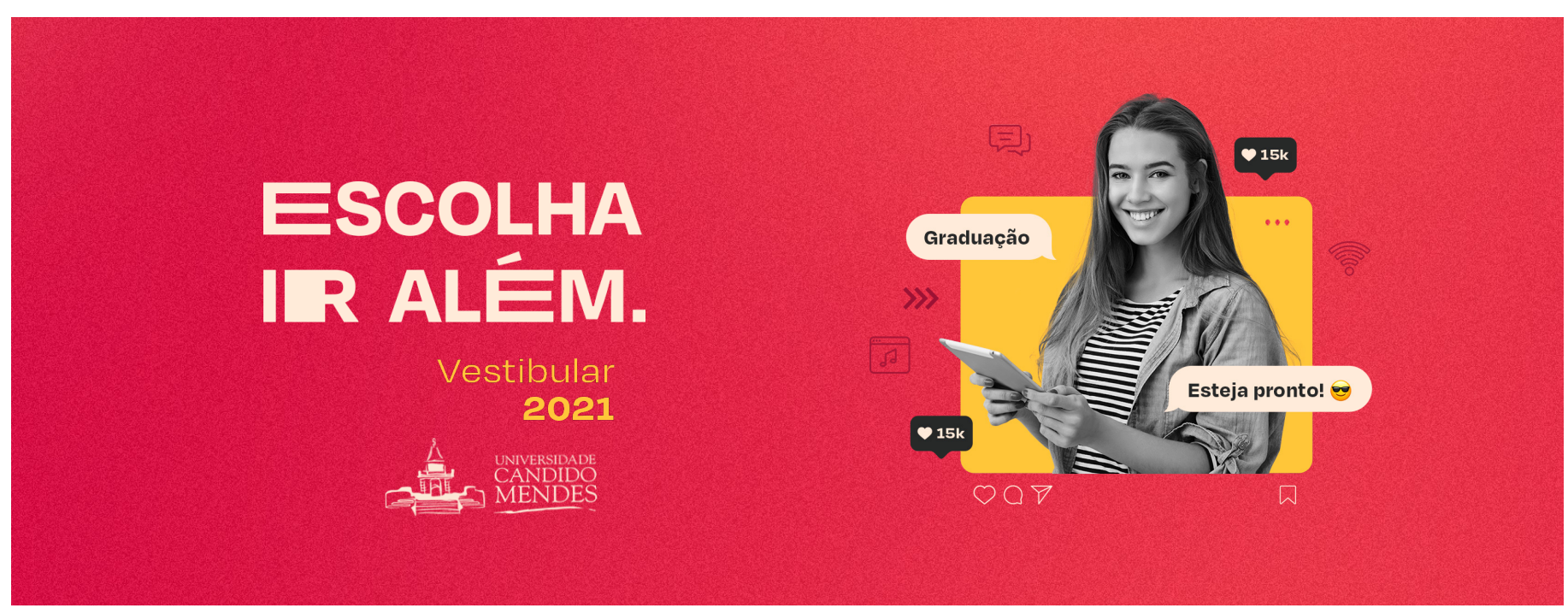


Tabela 1: Mudanças no funcionamento de estabelecimentos em Campos durante a pandemia.

\begin{tabular}{|c|c|c|c|c|c|}
\hline \multirow{2}{*}{$\begin{array}{l}\text { Setor de comércio varejista* } \\
\text { (número de estabelecimentos } \\
\quad \text { entrevistados) }\end{array}$} & \multirow[b]{2}{*}{$\begin{array}{c}\text { Funcionamento } \\
\text { total }\end{array}$} & \multicolumn{3}{|c|}{ Funcionamento com restrição } & \multirow[b]{2}{*}{$\begin{array}{c}\text { Não está } \\
\text { funcionando }\end{array}$} \\
\hline & & Horário & $\begin{array}{l}\text { Capacidade } \\
\text { de pessoas }\end{array}$ & $\begin{array}{c}\text { Horário e } \\
\text { capacidade }\end{array}$ & \\
\hline 1-Combustíveis e lubrificantes (2) & 1 & - & - & 1 & - \\
\hline $\begin{array}{l}\text { 2-Hipermercados, supermercados, } \\
\text { produtos alimentícios, bebidas e } \\
\text { fumo ( } 23 \text { ) }\end{array}$ & 4 & 2 & 3 & 13 & 1 \\
\hline $\begin{array}{l}\text { 3-Tecidos, vestuário e calçados } \\
\text { (12) }\end{array}$ & 0 & 2 & - & 4 & 6 \\
\hline 4-Móveis e eletrodomésticos (1) & 0 & - & - & 1 & - \\
\hline $\begin{array}{l}\text { 5-Artigos farmacêuticos, médicos, } \\
\text { ortopédicos, de perfumaria e } \\
\text { cosméticos (3) }\end{array}$ & - & - & - & 1 & 2 \\
\hline $\begin{array}{l}\text { 6-Livros, jornais, revistas e } \\
\text { papelaria (7) }\end{array}$ & - & - & 1 & 6 & - \\
\hline $\begin{array}{l}\text { 7-Equipamentos e materiais para } \\
\text { escritório, informática e } \\
\text { comunicação (6) }\end{array}$ & 1 & - & 2 & 2 & 1 \\
\hline $\begin{array}{l}\text { 8-Outros artigos de uso pessoal e } \\
\text { doméstico (8) }\end{array}$ & - & 3 & - & 3 & 2 \\
\hline $\begin{array}{l}\text { 9-Veículos, motocicletas, partes e } \\
\text { peças (4) }\end{array}$ & - & - & - & 3 & 1 \\
\hline 10-Material de construção (3) & - & - & - & 3 & - \\
\hline Total & 6 & 7 & 6 & 37 & 13 \\
\hline
\end{tabular}


Entre março e maio de 2020, devido a decretos estaduais e municipais que, em alguns casos, restringe e, em outros, suspende o funcionamento das lojas, a única forma possível de se comercializar certas categorias de produtos passou a ser por canais eletrônicos, conforme mostrado na Tabela 2. Diversos comércios que já utilizavam algum desses canais diversificaram as opções a fim de viabilizar o contato com os consumidores. Percebeu-se um aumento, principalmente, do uso do WhatsApp Messenger, Instagram e Marketplaces (como Mercado Livre, OLX, iFood, entre outros). Em contrapartida, certos estabelecimentos não conseguiram se adaptar tão rapidamente a essa nova realidade, tendo, assim, suas atividades encerradas.

\section{Tabela 2: Utilização de canais eletrônicos antes da pandemia versus durante a pandemia.}

\begin{tabular}{|c|c|c|c|c|c|c|c|}
\hline $\begin{array}{l}\text { Setor de comércio } \\
\text { varejista* } \\
\text { (número de } \\
\text { estabelecimentos } \\
\text { entrevistados) } \\
\end{array}$ & $\begin{array}{l}\text { Website } \\
\text { (antes/ } \\
\text { atual) }\end{array}$ & $\begin{array}{c}\text { WhatsApp } \\
\text { (antes/ } \\
\text { atual) }\end{array}$ & $\begin{array}{l}\text { Instagram } \\
\text { (antes/ } \\
\text { atual) }\end{array}$ & $\begin{array}{c}\text { Facebook } \\
\text { (antes/ } \\
\text { atual) }\end{array}$ & $\begin{array}{l}\text { Play } \\
\text { Store } \\
\text { (antes/ } \\
\text { atual) }\end{array}$ & $\begin{array}{c}\text { Marketplace } \\
\text { (antes/ } \\
\text { atual) }\end{array}$ & $\begin{array}{c}\text { Sem canal } \\
\text { eletrônico } \\
\text { (antes/ } \\
\text { atual) }\end{array}$ \\
\hline $\begin{array}{l}\text { 1-Combustiveis e } \\
\text { lubrificantes (2) }\end{array}$ & - & - & - & - & - & - & $2 / 2$ \\
\hline $\begin{array}{l}\text { 2-Hipermercados, } \\
\text { supermercados, } \\
\text { produtos } \\
\text { alimentícios, } \\
\text { bebidas e fumo (23) }\end{array}$ & $3 / 3$ & $14 / 19$ & $16 / 16$ & $9 / 8$ & - & $11 / 10$ & $3 / 1$ \\
\hline $\begin{array}{l}\text { 3-Tecidos, vestuário } \\
\text { e calçados (12) }\end{array}$ & $1 / 2$ & $8 / 10$ & $8 / 9$ & $9 / 7$ & $1 / 0$ & $1 / 1$ & $1 / 1$ \\
\hline $\begin{array}{l}\text { 4-Móveis e } \\
\text { eletrodomésticos } \\
\text { (1) }\end{array}$ & - & $1 / 1$ & $1 / 1$ & - & - & - & - \\
\hline $\begin{array}{l}\text { 5-Artigos } \\
\text { farmacêuticos, } \\
\text { médicos, } \\
\text { ortopédicos, de } \\
\text { perfumaria e } \\
\text { cosméticos (3) }\end{array}$ & $1 / 0$ & $1 / 1$ & $1 / 1$ & - & - & - & $2 / 2$ \\
\hline $\begin{array}{c}6 \text {-Livros, jornais, } \\
\text { revistas e papelaria } \\
(7) \\
\end{array}$ & $4 / 4$ & $3 / 4$ & $4 / 4$ & $5 / 5$ & $0 / 3$ & $0 / 3$ & $0 / 2$ \\
\hline $\begin{array}{c}\text { 7-Equipamentos e } \\
\text { materiais para } \\
\text { escritório, } \\
\text { informática e } \\
\text { comunicação (6) }\end{array}$ & $3 / 3$ & $3 / 3$ & $4 / 3$ & $4 / 4$ & - & $0 / 0$ & $2 / 2$ \\
\hline $\begin{array}{c}\text { 8-Outros artigos de } \\
\text { uso pessoal e } \\
\text { doméstico (8) } \\
\end{array}$ & $2 / 2$ & $5 / 4$ & $3 / 4$ & $2 / 3$ & $0 / 1$ & $2 / 4$ & $2 / 1$ \\
\hline $\begin{array}{c}\text { 9-Veículos, } \\
\text { motocicletas, partes } \\
\text { e peças (4) }\end{array}$ & $1 / 1$ & $2 / 2$ & $1 / 2$ & $2 / 2$ & - & $1 / 1$ & $2 / 2$ \\
\hline $\begin{array}{l}\text { 10-Material de } \\
\text { construção (3) }\end{array}$ & - & $2 / 3$ & - & $2 / 2$ & - & $0 / 1$ & $1 / 0$ \\
\hline Total & $15 / 15$ & $39 / 47$ & $38 / 40$ & $33 / 31$ & $1 / 4$ & $15 / 20$ & $15 / 13$ \\
\hline
\end{tabular}


Se, por um lado, a recomendação das autoridades públicas e dos órgãos de saúde fosse para que as pessoas permanecessem em suas casas, por outro, muitos estabelecimentos tiveram os atendimentos presenciais suspensos. Diante dessa realidade, houve uma redução no deslocamento de consumidores e a comercialização de determinados tipos de produto que, quando praticada, carecia de entregas em domicílio. Muitos negócios que antes realizavam apenas compras presenciais passaram a fazer entregas utilizando carros, pequenos caminhões ou motocicletas, conforme expresso na Tabela 3.

\section{Tabela 3: Utilização de sistema de entregas antes da pandemia versus durante a pandemia.}

\begin{tabular}{|c|c|c|c|c|c|}
\hline $\begin{array}{l}\text { Setor de comércio } \\
\text { varejista* } \\
\text { (número de } \\
\text { estabelecimentos } \\
\text { entrevistados) }\end{array}$ & $\begin{array}{c}\text { Carros e } \\
\text { caminhões } \\
\text { próprios } \\
\text { (antes/atual) }\end{array}$ & $\begin{array}{c}\text { Carros e } \\
\text { caminhões } \\
\text { de terceiros } \\
\text { (antes/atual) }\end{array}$ & $\begin{array}{c}\text { Motocicletas } \\
\text { próprias } \\
\text { (antes/atual) }\end{array}$ & $\begin{array}{c}\text { Motocicletas } \\
\text { de terceiros } \\
\text { (antes/atual) }\end{array}$ & $\begin{array}{r}\text { Sem sistema } \\
\text { de entregas } \\
\text { (antes/atual) }\end{array}$ \\
\hline $\begin{array}{l}\text { 1-Combustíveis e } \\
\text { lubrificantes (2) }\end{array}$ & - & - & - & - & $2 / 2$ \\
\hline $\begin{array}{c}\text { 2-Hipermercados, } \\
\text { supermercados, produtos } \\
\text { alimentícios, bebidas e } \\
\text { fumo }(23)\end{array}$ & $9 / 10$ & $3 / 2$ & $5 / 5$ & $12 / 12$ & $2 / 2$ \\
\hline $\begin{array}{l}\text { 3-Tecidos, vestuário e } \\
\text { calçados (12) }\end{array}$ & $2 / 6$ & $1 / 0$ & $0 / 2$ & $3 / 5$ & $7 / 2$ \\
\hline $\begin{array}{c}\text { 4-Móveis e } \\
\text { eletrodomésticos (1) }\end{array}$ & $1 / 0$ & $1 / 0$ & - & - & - \\
\hline $\begin{array}{l}\text { 5-Artigos farmacêuticos, } \\
\text { médicos, ortopédicos, de } \\
\text { perfumaria e cosméticos } \\
\text { (3) }\end{array}$ & - & - & $1 / 1$ & - & $2 / 2$ \\
\hline $\begin{array}{c}\text { 6-Livros, jornais, revistas } \\
\text { e papelaria (7) }\end{array}$ & $0 / 2$ & - & $1 / 1$ & $1 / 5$ & $5 / 1$ \\
\hline $\begin{array}{c}\text { 7-Equipamentos e } \\
\text { materiais para escritório, } \\
\text { informática e } \\
\text { comunicação }(6)\end{array}$ & $5 / 4$ & $0 / 1$ & $1 / 1$ & - & $1 / 1$ \\
\hline $\begin{array}{l}\text { 8-Outros artigos de uso } \\
\text { pessoal e doméstico (8) }\end{array}$ & $3 / 3$ & $0 / 0$ & $0 / 1$ & $0 / 1$ & $5 / 4$ \\
\hline $\begin{array}{c}\text { 9-Veículos, motocicletas, } \\
\text { partes e peças (4) }\end{array}$ & $1 / 2$ & - & - & - & $3 / 2$ \\
\hline $\begin{array}{c}\text { 10-Material de construção } \\
\text { (3) }\end{array}$ & $2 / 2$ & $1 / 1$ & $1 / 1$ & $0 / 1$ & - \\
\hline Total & $23 / 29$ & $6 / 4$ & $9 / 12$ & $16 / 24$ & $27 / 16$ \\
\hline
\end{tabular}


Na atual conjuntura do comércio local, notam-se desdobramentos sociais importantes, como o desemprego. Do total de comércios pesquisados, 36 (52,2\%) deles precisaram dispensar algum funcionário; já, nos $33(47,8 \%)$ comércios restantes, não houve dispensa de funcionários até o momento da entrevista.

A redução do transporte urbano, seja de produtos, seja de pessoas, significa menos pessoas nas ruas, menos atividade econômica e menos demanda por combustíveis. Não se pode negar a melhoria para o ambiente em termos de qualidade do ar e de redução da poluição sonora, em contrapartida, a diminuição na demanda energética tem sido compensada negativamente pelo aumento da produção de lixo orgânico e inorgânico, como embalagens e materiais hospitalares.

Para lidar com essa pandemia ponderando questões de saúde pública e de equilíbrio econômico, as escalas federal, estaduais e municipais do poder público precisam adotar estratégias eficazes para minimizar os impactos em toda a sociedade. Nesse sentido, precisa-se refletir sobre alguns desafios importantes provocados pela COVID-19 em escala global e analisar como isso interfere nas relações sociais, econômicas e ambientais em um nível local. Tais questões devem ser enxergadas e discutidas considerando o papel do Estado enquanto formulador, executor e regulador de políticas socioeconômicas que visam pelo bem-estar social (MISCALI et al., 2020).

\section{Considerações finais}

Este estudo aponta para a mudança nos padrões de venda e de transporte de produtos durante a pandemia da COVID-19 em Campos dos Goytacazes e os respectivos desdobramentos em níveis econômicos, sociais e ambientais. Diante da situação de incertezas quanto à propagação de uma doença invisível e aos riscos constantes para a saúde pública, os governos estaduais e municipais publicaram diversos decretos relacionados à movimentação de pessoas e de bens. Dessa forma, foi possível observar que a atual conjuntura das relações sociais permeada pelo distanciamento social como forma de preservação da saúde impactou fortemente as relações comerciais e econômicas da cidade. Como consequência, os comerciantes locais tiveram que se adaptar às condições impostas a fim de reduzir os danos causados.

A presente pesquisa buscou diagnosticar a realidade das vendas e dos transportes de produtos em uma cidade média, contudo, os resultados encontrados não podem ser generalizados. Sugere-se que trabalhos futuros possam realizar uma análise dessa questão na referida cidade utilizando uma amostra maior de lojistas. Incentiva-se, também, que outros pesquisadores tragam novas contribuições, expandindo o estudo para outras cidades ou estados. Por fim, perceberam-se evidências de como essa pandemia já impactou a economia tanto em nível global como local. Ainda não se sabe ao certo quais serão os efeitos disso em médio e longo prazos. Contudo, assim como os lojistas, a gestão pública precisará lidar com esses efeitos pós-pandemia, e os formuladores de políticas públicas terão que deixar o campo de disputa política para repensar e reorganizar o planejamento e o desenvolvimento regional.

\section{Agradecimentos}

Os autores agradecem à Coordenação de Aperfeiçoamento de Pessoal de Nível Superior (CAPES), ao Conselho Nacional de Desenvolvimento Científico e Tecnológico (CNPq) e à Fundação de Amparo à Pesquisa do Estado do Rio de Janeiro (FAPERJ) pelo suporte financeiro para esta pesquisa. Agradecem também à Federação das Câmaras de Dirigentes Lojistas (FCDL) do estado do Rio de Janeiro pela interface entre pesquisador e empresa.

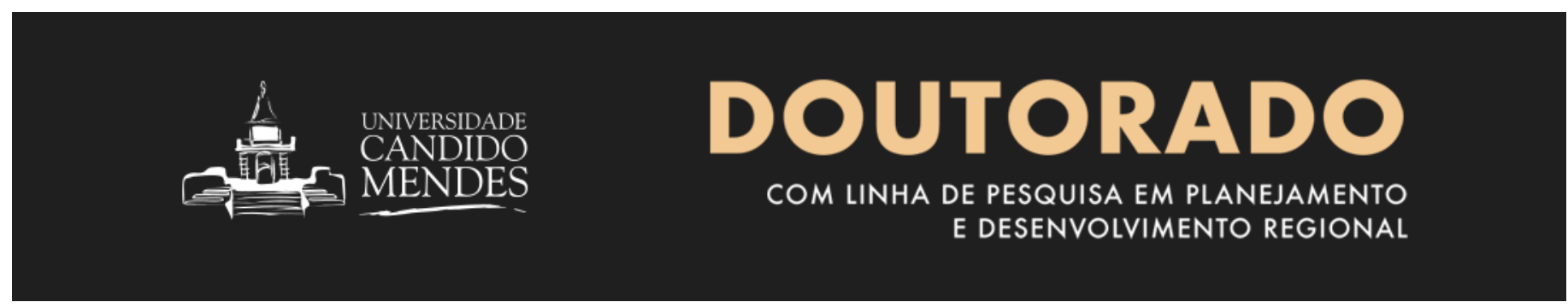




\section{Referências}

ALI, I.; ALHARBI, O. M. L. COVID-19: Disease, management, treatment, and social impact. Science of the Total Environment, Amsterdam, v. 728, p. 138861, ago. 2020.

ARNOLD, F. et al. Simulation of B2C e-commerce distribution in Antwerp using cargo bikes and delivery points. European Transport Research Review, Berlin, v. 10, n. 2, p. 1-13, 2018.

CASTILLO et al. Crowdsourcing last mile delivery: strategic implications and future research directions. Journal of Business Logistics, New Jersey, V. 39, n. 1, p. 7-25, 2018

COMI, A.; NUZZOLO, A. Exploring the Relationships Between e-shopping Attitudes and Urban Freight Transport. Transportation Research Procedia, Amsterdam, v. 12, p. 399-412, 2016.

CRAINIC, T. G.; MONTREUIL, B. Physical internet enabled Hyperconnected City logistics. Transportation Research Procedia, Amsterdam, v. 12, p. 383398, 2016.

DANTAS, G. et al. The impact of COVID-19 partial lockdown on the air quality of the city of Rio de Janeiro, Brazil. Science of the Total Environment, Amsterdam, v. 729, p. 139085, ago. 2020.

GAMMELGAARD, B. The emergence of city logistics: the case of Copenhagen's Citylogistik-kbh. International Journal of Physical Distribution \& Logistics Management, Bingley, v. 45, n. 4, p. 333-351, mai. 2015.

GIL, A. C. Como elaborar projetos de pesquisa. 5. ed. São Paulo: Atlas, 2010.

IBGE - Instituto Brasileiro de Geografia e Estatística. Resultado dos Dados Preliminares do Censo - 2010. IBGE Cidades, Campos dos Goytacazes RJ, [2020?]. Disponível em: https://cidades.ibge.gov.br/brasil/rj/campos-dos-goytacazes/panorama. Acesso em: 20 maio 2020.

IGNAT, B.; CHANKOV, S. Do e-commerce customers change their preferred last-mile delivery based on its sustainability impact? The International Journal of Logistics Management, Bingley, v. 31, n. 3, p. 521-548, ago. 2020.

IVANOV, D. Predicting the impacts of epidemic outbreaks on global supply chains: A simulation-based analysis on the coronavirus outbreak (COVID-19/ SARS-CoV-2) case. Transportation Research Part E, Oxford, v. 136, p. 101922, abr. 2020.

KISSLER, S. M. et al. Projecting the transmission dynamics of SARS-CoV-2 through the postpandemic period. Science, Washington, v. 368, n. 6493, p. 860-868, mai. 2020.

MASSON, R. et al. Optimization of a city logistics transportation system with mixed passengers and goods. EURO Journal on Transportation and Logistics, Berlin, v. 6, p. 81-109, 2017.

MEE, L. Y.; HUEI, C. T. A profile of the internet shoppers: evidence from nine countries. Telematics and Informatics, 0xford, v. 32, n. 2, p.344-354, 2015.

MISCALI, S. R. S. et al. A gestão ambiental a partir do orçamento público: uma análise das despesas referentes ao orçamento do município de São João da Barra. Boletim Petróleo, Royalties e Região, Campos dos Goytacazes, v. 17, n. 65, p. 14, 2020

MOURA, H. N. et al. Resultantes da greve dos caminhoneiros (2018): um hibridismo de estatística bilionária e o óleo diesel em face à macroeconomia. Research, Society and Development, Itabira, v. 8, n. 7, p. 14, 2019.

NAKADA, L. Y. K.; URBAN, R. C. COVID-19 pandemic: Impacts on the air quality during the partial lockdown in São Paulo state, Brazil. Science of the Total Environment, Amsterdam, v. 730, p. 139087, ago. 2020.

OLIVEIRA, L. K. et al. Analysis of the potential demand of automated delivery stations for e-commerce deliveries in Belo Horizonte, Brazil. Research in Transportation Economics, Stamford, v. 65, p. 32-43, 2017.

SHARMA, S. et al. Effect of restricted emissions during COVID-19 on air quality in India. Science of the Total Environment, Amsterdam, v. 728, p. 138878, ago. 2020.

TOBÍAS, A. et al. Changes in air quality during the lockdown in Barcelona (Spain) one month into the SARS-CoV-2 epidemic. Science of the Total Environment, Amsterdam, v. 726, p. 138540, jul. 2020.

ZAMBRANO-MONSERRATE, M. A.; RUANO, M. A.; SANCHEZ-ALCALDE, L. Indirect effects of COVID-19 on the environment. Science of the Total Environment, Amsterdam, v. 728, p. 138813, ago. 2020. 


\section{Editor}

Valdir Júnio dos Santos

Universidade Candido Mendes - Campos dos Goytacazes

\section{Conselho Editorial}

Angela Moulin Simões Penalva Santos

Universidade do Estado do Rio de Janeiro - UERJ

\section{Christian Luiz da Silva}

Universidade Tecnológica Federal do Paraná - UTFPR

Denise Cunha Tavares Terra

Universidade Estadual do Norte-Fluminense - UENF

Edna Maria Ramos de Castro

Universidade Federal do Pará - UFPA

Frédéric Jean Marie Monié

Universidade Federal do Rio de Janeiro - UFRJ

Helder Queiroz Pinto Junior

Universidade Federal do Rio de Janeiro - UFRJ

Isa de Oliveira Rocha

Universidade do Estado de Santa Catarina - UDESC

\section{Jeroen Johannes Klink}

Universidade Federal do ABC - UFABC

João Figueira de Sousa

Universidade Nova de Lisboa - UNL

\section{João José de Assis Rangel}

Universidade Candido Mendes - Campos dos Goytacazes

\section{José Gutman}

Agência Nacional do Petróleo, Gás Natural e Biocombustíveis - ANP

Lia Valls

Fundação Getúlio Vargas - FGV

Luciano Dias Losekann

Universidade Federal Fluminense - UFF

Maria Amélia Rodrigues da Silva Enriquez

Universidade Federal do Pará - UFPA

Marilia Steinberger

Universidade de Brasília - UnB

\section{Paulo Gusmão}

Universidade Federal do Rio de Janeiro - UFRJ

\section{Rodrigo Anido Lira}

Universidade Candido Mendes - Campos dos Goytacazes

\section{Rodrigo Valente Serra}

Agência Nacional do Petróleo, Gás Natural e Biocombustíveis - ANP Centro

Federal de Educação Tecnológica Celso Suckow da Fonseca - CEFET/RJ)

\section{Rosana Baeninger}

Universidade Estadual de Campinas - Unicamp

\section{Rosélia Piquet}

Universidade Candido Mendes - Campos dos Goytacazes

\section{Silvia Gorenstein}

Universidad Nacional del Sur - Argentina

Suzana Quinet de Andrade Bastos

Universidade Federal de Juiz de Fora - UFJF

Vera Lucia Alves França

Universidade Federal de Sergipe - UFS

Virginia Elisabeta Etges

Universidade de Santa Cruz do Sul - UNISC

\section{Yann Fournis}

Université du Quebec à Rimouski - UQAR

Yves Fauré

Université Paris 1 Panthéon-Sorbonne

\section{Bibliotecária responsável}

Flávia Mastrogirolamo

Universidade Candido Mendes - Campos dos Goytacazes

\section{Editoração/ Diagramação}

Daieni Marques e João Pedro Cabral da Silva - Marketing

Universidade Candido Mendes - Campos dos Goytacazes

\section{Revisora gramatical \\ Maria Marta Garcia de Assis Rangel}

Universidade Candido Mendes - Campos dos Goytacazes

\section{Bolsista de iniciação científica}

Maria Eduarda Quintanilha Ribeiro

Universidade Candido Mendes - Campos dos Goytacazes

\section{Escopo}

O Boletim Petróleo, Royalties e Região, vinculado ao Mestrado Profissional em Planejamento Regional e Gestão de Cidades da Universidade Candido Mendes (UCAM - Campos dos Goytacazes), é fruto da preocupação com a difusão de dados e informações técnicas para o debate sobre a distribuição dos royalties na região petrolífera do Estado do Rio de Janeiro. Dessa forma, se configura como um veículo de publicação de natureza acadêmica e técnica, primando pela qualidade de seus artigos e sua periodicidade desde setembro de 2003. 0 Boletim tem por foco editorial pesquisas originais, teóricas ou empíricas, voltadas para planejamento regional e urbano, petróleo e outros minerais, royalties e outras participações governamentais, economia regional, políticas públicas e áreas afins, dentro de uma visão multidisciplinar das temáticas relacionadas ao seu escopo.

\section{Periodicidade}

0 Boletim é publicado trimestralmente de forma regular e ininterrupta em versão exclusivamente eletrônica.

\section{Diretrizes para os autores}

Os textos recebidos são apreciados inicialmente pelo editor-chefe, que encaminhará para avaliação por membros do Conselho Editorial e, eventualmente, por pareceristas ad hoc.

As normas de apresentação do texto para o envio do artigo são:

- 0 arquivo deve ser enviado em formato 'DOC' ou 'DOCX'.

- A primeira página deve apresentar: a) título do trabalho; b) autoria: nome completo do(s) autor(es), formação acadêmica, filiação institucional, e-mail, telefone e endereço para correspondência.

- A segunda página deve conter: a) título em português e inglês; $b$ ) resumo em português e abstract em inglês, contendo entre 100 e 150 palavras, com indicação de 3 a 5 palavras-chave.

- Os artigos devem ter entre 11 mil e 15 mil caracteres com espaços (incluindo notas e referências bibliográficas).

- Formatação: tamanho do papel: A4 (21 x 29,7 cm); margens superior e esquerda: $3 \mathrm{~cm}$; inferior e direita: $2 \mathrm{~cm}$; Fonte: Times New Roman, corpo 12; Espaçamentos: 1,5 entre linhas.

- As referências bibliográficas devem estar de acordo com as normas estabelecidas pela Associação Brasileira de Normas Técnicas (ABNT). - As notas, quando houver, devem ser colocadas ao final do texto (Nota de fim).

- Ilustrações e tabelas devem ser enviadas em arquivos separados.

- Ilustrações devem ser enviadas em JPG, com resolução mínima de 96 dpi. - 0 encaminhamento dos textos para o Boletim implica a autorização para publicação e aceitação de eventuais edições necessárias para adequação ao formato do Boletim e ao seu padrão editorial.

\section{Author Guidelines}

The articles submitted are accepted for consideration firstly by the Editor in chief, who refers them to be evaluated by members of the editorial 
board, and, eventually, by ad hoc referees. The formatting rules to send the article are the following:

- The file must be sent in 'DOC" or "DOCX' format.

- The first page must present: a) title of the work; b) authorship: full name of the author(s), academic degree, institutional affiliation, e-mail address, telephone number, and full postal address.

- The second page must contain: a) title in English; b) abstracts in English, comprising 100 to 150 words and also 3 to 5 keywords.

- The articles should be in the regions of 11,000 to 15,000 characters with spaces (including notes and bibliographic Referências).

- Formatting: paper size: A4 (21.0 cm by $29.7 \mathrm{~cm})$; top left margin: $3.0 \mathrm{~cm}$; bottom right margin: $2.0 \mathrm{~cm}$; font: Times New Roman, 12 - point font size; spacing: $1.5 \mathrm{~cm}$ between lines.

- Bibliographic Referências must be in accordance with the standards established by the Brazilian Association of Technical Standards (Associação Brasileira de Normas Técnicas - ABNT-NBR 6023).

\section{Instrucciones para los Autores}

Los textos recibidos son evaluados inicialmente por el editor en jefe, que los encaminará para valoración por los miembros del Comité Editorial y, eventualmente, por árbitros ad hoc. Las normas de presentación del texto para envío del artículo son las que se siguen:

- Los archivos se deben enviar en formato 'DOC' o "DOCX'.

- La primera página debe presentar: a) título del trabajo; b) autoría: nombre completo del autor, formación académica, afiliación institucional, correo electrónico, teléfono y dirección para correspondencia.

- La segunda página debe incluir: a) título en Español e Inglés; b) resumen en Español y abstract en Inglés entre 100 (cien) y 150 (ciento cincuenta) palabras, incluyéndose entre 3 (tres) y 5 (cinco) palabras claves.

- Los artículos deben tener como mínimo 11 mil y como máximo 15 mil caracteres con espacios (incluyendo notas y referencias bibliográficas). - Formateo: hoja tamaño A4 (21,0 x 29,7cm); márgenes superior e izquierdo: $3 \mathrm{~cm}$; inferior y derecho 2cm; Times New Roman 12; interlineado 1,5.

- Referencias bibliográficas deben ser presentadas de acuerdo a las normas establecidas por la Asociación Brasileña de Normas Técnicas - ABNT-NBR 6023 (Associação Brasileira de Normas Técnicas).

Os artigos devem ser enviados exclusivamente para o e-mail: boletim@ucam-campos.br 